\title{
Trends in prevalence of prehypertension and hypertension, awareness, treatment, control and cardiovascular risk factors in relatively large sample of Iranian menopausal women: 2001-2016
}

Maryam Eghbali-Babadi

Isfahan University of Medical Sciences

Alireza Khosravi

Isfahan University of Medical Sciences

Awat Feizi

Isfahan University of Medical Sciences

Hassan Alikhasi

Isfahan University of Medical Sciences

Narges Kheirollahi ( $\nabla$ n.kheirollahi@nm.mui.ac.ir)

isfahan university of medical science https://orcid.org/0000-0002-6691-7677

Nizal Sarrafzadegan

Isfahan University of Medical Sciences

Research article

Keywords: Blood Pressure, Epidemiology, Prehypertension, Hypertension, Risk Factors, Menopause, Women

Posted Date: July 5th, 2019

DOI: https://doi.org/10.21203/rs.2.10835/v1

License: (c) (i) This work is licensed under a Creative Commons Attribution 4.0 International License. Read Full License 


\section{Abstract}

Background prehypertension and hypertension are risk factors for cardiovascular disease. Despite its importance, hypertension is often underestimated and undiagnosed, especially in women. This study was designed to determine trends in prevalence of prehypertension and hypertension, awareness, treatment, control and cardiovascular risk factors among the Iranian menopausal women. Methods This repeated Cross-sectional study was conducted on 8073 individuals which 1013 of these subjects were menopausal women older than 40, in Iran, in the years of 2001, 2007 and 2016. Samples were selected through random, multistage, cluster sampling. The data collected by the questionnaire included clinical information and blood pressure was determined via arm digital blood pressure monitors. Results The prevalence of hypertension was in the years 2001, 2007 and 2016, respectively \% 52.6, \% 49.0 and \% 51.6, no significant changes were observed( $p=0.628)$. The prevalence of Prehypertension over these years (\% 56.6, \%.53.3 and \% 42.2) was significantly decreased $(p=0.006)$. The Trends of awareness $(p=0.015)$, treatment $(p=0.009)$ and control $(p<0.001)$ of hypertension in menopausal women with high blood pressure has significantly increased. Despite the increasing trends of drug treatment for hypertension, hypertension is uncontrolled in more than a third of subjects. Hyperlipidemia, diabetes mellitus and Body mass index increased significantly from 2001 to 2016 among the menopausal women. Conclusions The results showed that hypertension and Prehypertension are highly prevalent among Iranian menopausal women and markedly increased with age. Interventional population-based approaches are needed to improve knowledge and efficient practice that may help lower the risk for hypertension and CVD among this at risk population.

\section{Background}

Hypertension is a major risk factor for cardiovascular diseases. According to the World Health Organization (WHO), in 2012, one out of every 3 adults in the world has high blood pressure and it is predicted that this number will escalate to more than 1.56 billion by the year 2025 (1). In addition to hypertension, prehypertension is also known as another important risk factor for cardiovascular diseases $(2,3)$. In recent years, several studies have reported the increased risk of cardiovascular diseases in people with prehypertension (4-6). Before menopause, the prevalence of hypertension in women is much lower than in men, however, its prevalence increases significantly in postmenopausal women and equates to men (5). Postmenopausal women are at increased risk of hypertension and around $50 \%$ suffer from high blood pressure (7). Recent studies showed that $25 \%$ of women worldwide and more than $75 \%$ of women over the age of 60 in the United States have hypertension $(4,8)$. In a 3-year study in 4,680 perimenopause Spanish women, $27.3 \%$ of those who had normal blood pressure before menopause were prehypertensive in the postmenopausal period. This finding confirms the increase of prehypertension in postmenopausal period (9). With the growth of the world's older population, about 25 million women reach menopause every year, and with an increase of 47 million new cases annually, this figure is predicted to reach 1.2 billion in 2025 (10). menopause is a normal, natural event, defined as the final menstrual period(6) and usually occurs at the age of 45-55(11) Postmenopausal women were defined as not having experienced a period for 12 months or more(6).

Studies on the causes of hypertension in postmenopausal women indicate that a combination of factors such as the reduced vasodilator effect of endogenous estrogens, increased arterial sclerosis, increased salt sensitivity, decreased production of endothelial vascular nitric oxide, and increased receptor responses to angiotensin II may contribute to the increased systolic blood pressure (12). Furthermore, postmenopausal women are more predisposed to other cardiovascular risk factors such as dyslipidemia, diabetes mellitus and obesity (5).

Hypertension is usually asymptomatic but can be detected without needing advanced diagnostic equipment and can be easily treated and controlled with adherence to healthy lifestyle and medication recommendations (13). According to the WHO, less than $50 \%$ of people with hypertension are aware of their condition, $25 \%$ receive treatment, and less than $12.5 \%$ of such individuals manage the disease effectively (14). Considering the increasing global prevalence of hypertension and given the fact that most people with hypertension are not aware of their condition and poorly manage their disease, and also given the increasing population of older people and postmenopausal women, and the risk of hypertension in this period, this study aimed to determine the prevalence of prehypertension, hypertension, awareness, treatment, and control of hypertension, and risk factors for cardiovascular diseases among postmenopausal women in Isfahan, one of the major metropolises of Iran. 
The results of this study would be helpful in planning effective community interventions for primary and secondary prevention of hypertension.

\section{Methods}

At this repeated cross-sectional study, the data from three independent samples in 2001, 2007 and 2016 were used to determine a trend over 15-year of prevalence of HTN and prehypertension, awareness, treatment and control of HTN in the menopausal women of Isfahan. The random cluster sampling was used for selection of study's participants. A total of 8627 individuals participated in these three studies. After the integration of data related to these three studies, management and processing of data were performed. Then, errors and data inconsistencies were eliminated, and the final file was prepared for data analysis. Finally, the data obtained from 8073 individuals were used to determine trends of HTN. In Isfahan healthy heart program in 2001, 2007 and 2016, 3703(1655 female - 1772 male), 2660(1252 female - 1287 male) and 2107(1017 female - 1090 male) adult residents of Isfahan, Iran were interviewed respectively. But, only 397, 298 and 318 women was menopause.

The inclusion criteria were: women over 40 years old, who have not been menstruating for at least 12 months, and being menopausal confirmed by a physician. Exclusion criteria include: fasting or having a diet either for obesity or for weight loss at the time of the study, and having a known comorbidity such as kidney failure and cancer. Methods for the sample size estimation and sampling; the procedures for measuring the blood pressure, height and weight; and data collection methods of the cross-sectional studies have been fully described in the earlier published articles(15-18)

\subsection{Definitions}

Definitions Following JNC-7 report guidelines, hypertension was defined as a systolic blood pressure (SBP) $\geq 140 \mathrm{mmHg}$, and/or diastolic blood pressure (DBP) $\geq 90 \mathrm{mmHg}$, and/or use of antihypertensive medications (19). Prehypertension was defined as not being on antihypertensive drugs and having an SBP of 120-139 mm Hg and/or DBP of $80-89 \mathrm{~mm} \mathrm{Hg}$. Body mass index (BMI) was calculated as the weight in kilograms divided by height in meters squared $(\mathrm{kg} / \mathrm{m} 2)$. Prevalence of awareness of hypertension was defined as the proportion of women with hypertension who had a self-report of any previous diagnosis of hypertension by a health care professional. Treatment of hypertension was defined as self-reported use of antihypertensive medications with regular, irregular and non-intake of medication, among hypertensive participants who were aware of being hypertensive. Prevalence of Control of hypertension was defined as the proportion of women with hypertension who had a systolic BP $<140 \mathrm{~mm} \mathrm{Hg}$ and a diastolic BP $<90 \mathrm{~mm} \mathrm{Hg}$ in hypertensive women who were under treatment (20).

\subsection{Data collection, variables, and tools}

We used the Data collection, variables, and tools previously described by Eghbali in 2018(18)

\subsection{Statistical analysis}

Data was presented as mean \pm standard deviation for continuous variables and frequency (percentage) for categorical variables. In order to achieve the research results; the collected data were coded and were analyzed using. One way ANOVA was used for comparing continuous normally distributed data between three time points and Bonferroni post hoc test was used for pairwise comparisons Chi-square test was used for comparing the prevalence of pre and hypertension risk factors between study time points. Multiple binary logistic regressions were used to evaluate the risk factors of pre and hypertension. SPSS software (version 18.0, SPSS Inc., Chicago, IL, USA), was used for data analysis and p-values less than 0.05 were considered to be statistically significant. 


\section{Results}

A total of 1013 menopausal women older than 40 years participated in this study. The minimum and maximum menopausal ages in the years 2001, 2007, and 2016 were 27 and 67, 29 and 60, and 28 and 65 years, respectively.

Moreover, the mean age of menopause (permanent cessation of menstruation) was $46.95 \pm 5.63,47.06 \pm 5.62$, and $48.31 \pm$ 6.26 years at 2001, 2007 and 2016, respectively. The mean BMI of the participants for the respective years was also $28.80 \pm$ $5.07,28.65 \pm 4.41$, and $29.93 \pm 4.62$. Furthermore, the mean systolic blood pressure of the participants in the respective years were $131.22 \pm 22.63,124.09 \pm 20.59$ and $126.64 \pm 19.32 \mathrm{~mm} \mathrm{Hg}$, while their mean diastolic blood pressures were $81.87 \pm$ $13.93,77.23 \pm 11.66$, and $10 \pm 74.24 \mathrm{~mm} \mathrm{Hg}$, respectively. The demographic and clinical characteristics of the participants for the three respective years are presented and compared in the Table 1.

The prevalence of diabetes mellitus was $15.9 \%, 15.8 \%$ and $27 \%$, in 2001, 2007, and 2016, while the prevalence of hyperlipidemia was $29.2 \%, 35.6 \%$ and $49.4 \%$ in the same years, respectively. Moreover, the prevalence of positive family history of hypertension among the participants in the three respective years was $31.2 \%, 51.7 \%$, and $66.7 \%$. All the three variables showed a significant increase in menopausal women $((P=0.001)$. However, the use of saltshaker showed a significant decrease during these years $(P=0.001)$.

As presented in table 2, the prevalence of prehypertension in menopausal women shows a decreasing trend from the 2001 to the 2016 survey so that it was $59.6 \%$ in 2001 but respectively decreased to $53.3 \%$ and $42.2 \%$ in 2007 and 2016 . However, the prevalence of hypertension in menopausal women did not significantly change during the three respective years so that it was $52.6 \%, 49 \%$ and $51.6 \%$, in 2001, 2007, and 2016, respectively. Furthermore, during the three respective years, the prevalence of hypertension significantly increased with age, with the highest prevalence among women over the age of 70 years (Fig. 1).

Table 3 shows that the prevalence of hypertension awareness among the menopausal women was $74.6 \%$ in 2001 , but significantly increased to $77.4 \%$ and $86.6 \%$ in 2007 and 2016, respectively. Consistently, the prevalence of well-controlled hypertension was $28.8 \%$ in 2001 and significantly increased to $50.4 \%$ and $62.0 \%$ in 2007 and 2016, respectively. Moreover, in $2001,73.7 \%$ of menopausal women who were under medical treatment for hypertension used their medications regularly. This rate was $71.9 \%$ in 2007 and significantly increased to $86.6 \%$ in 2016 .

Table 4 illustrated the prevalence of cardiovascular risk factors among hypertensive menopausal women in the three respective years. The prevalence of diabetes mellitus in menopausal women was $19.6 \%$ in 2001 and respectively increased to $21.9 \%$ and $34.8 \%$ in 2007 and 2016 ( $P=0.002$ ). Moreover, the prevalence of hyperlipidemia was $34.4 \%$ in 2001 and respectively increased to $43.6 \%$ and $57.9 \%$ in 2007 and 2016 . The, prevalence of positive family history of hypertension was also $39.2 \%$ in 2001 and respectively increased to $53.4 \%$ and $68.5 \%$ in 2007 and 2016 ( $P<0.001)$. Logistic regression (Table 5) showed that each year increase in age of menopausal women resulted in an increase of $7.7 \%, 7.0 \%$ and $12.5 \%$ in the prevalence of hypertension during the three respective years. Also, in 2001 every unit increase in BMI was associated with an increase of $6.7 \%$ in the chance of having hypertension. This rate was decreased to $6.0 \%$ and $5.9 \%$ in 2007 and 2016 , respectively. Furthermore, in 2001 the chance of having hypertension was $143.3 \%$ in menopausal women with a positive family history of hypertension. This rate was increased to $153.4 \%$ in 2016 . Besides, in 2016, the risk of having hypertension was $84.8 \%$ for diabetics, as compared with non-diabetic menopausal women.

\section{Discussion}

Age at menopause in our studied sample is similar to previous estimates reported for other Iranian populations .In a crosssectional study on 960 menopausal women in 2015 in Isfahan mean and median of natural menopause age were 48.66 and 48 years, respectively (22). In the present study, the mean age at permanent cessation of menstrual periods has significantly been increased and reached by 48 years in 2016. This finding was consistent with two earlier Iranian studies published in 2008 and $2013(14,15)$. Consistently, a meta-analysis published in 2011 evaluated the mean age of menopause in a number of countries and reported that the mean age of menopause was 48.2 in Iran, 47.16 in Pakistan, 47.3 in the United Arab

Page $4 / 14$ 
Emirates, 47.8 in Turkey, 48.22 in India, 49 in Russia, 50 in Sweden, 50.9 in the Netherlands, 51 in Finland, 51.7 in Spain, 52 in France, and 52.6 in the United States. Given these data, and compared with other countries in the region, the mean age of menopause seems suitable in Iran although it is lower than in advanced countries. This study has not only shown the trend of increasing age at menopause over time, but it also suggested that factors such as increased women's life expectancy, improved people's diet and public health may play important roles in this trend (23). It seems that a combination of factors such as genetics, ethnicity, smoking behavior, socioeconomic status, and fertility history may affect the age of menopause. The present study showed a significant increasing trend both in BMI and in the risk of hypertension in postmenopausal women. An earlier study also showed that the mean women's BMI was $22.1 \mathrm{~kg} / \mathrm{m} 2$ in 1975 and increased to 24.4 in 2014 (24). There is also more evidence of the increasing trend of BMI in many societies and on its direct association with the incidence of prehypertension and hypertension (25). In this regard, a study reported that -compared to those with a BMl<25the risk of hypertension would respectively be increased by $67 \%$ and $150 \%$ in subjects with a BMI of $25-30$ and a BMl> 30 (26). Another study on the prevalence of cardiovascular risk factors in Russian patients with hypertension also reported hypertriglyceridemia, hyperglycemia, and obesity as the major risk factors associated with hypertension (27).

The present study showed that the mean systolic and diastolic blood pressures of postmenopausal women were significantly lower in 2016 than in 2001. Consistently, a study on the prevalence of hypertension in adult population of the United States showed that -from 1999 to 2010- the mean SBP and DBP decreased both in men and women, and this decline was specially greater in women (28). Several studies in Central and Eastern Europe, Latin America and the Caribbean area, Central Asia, the Middle East and North Africa have also confirmed the slight decline in the mean blood pressure among women during the recent decades (29).

The present study showed an increasing trend in the prevalence of diabetes and hyperlipidemia in postmenopausal women from 2001 to 2016. Moreover, in 2016, the risk of hypertension was higher in diabetic patients than non-diabetics. Studies on the global incidence of diabetes mellitus have also shown that the incidence of diabetes in women has increased from $5 \%$ in 1980 to $7.9 \%$ in 2014 (24). The prevalence of hyperlipidemia has also increased in China (25). It has also been shown that the chances of developing cardiovascular diseases will respectively increase up to $107 \%$ and $48 \%$ in postmenopausal women with diabetes and hyperlipidemia (26).

The results of this study revealed an increase in the positive family history of hypertension in postmenopausal women from 2001 to 2016, and in 2016 nearly two-thirds of postmenopausal women had a positive family history of HTN in one of their first-degree relatives (i.e. parents and siblings). Moreover, as presented in the current study, in 2001 and 2016 the chance of having hypertension was higher in women with a positive family history of HTN than those without a family history. Consistently, Zhou et al., have also reported that the risk of CVD will be increased by $56 \%$ in postmenopausal women with a positive family history of HTN (26).

The results of the present study showed that salt intake decreased in menopausal women from 2001 to 2016, and over time, a smaller percentage of postmenopausal women used a saltshaker while eating. These results are consistent with two earlier studies that investigated the use of salt by Iranian women. The first study was conducted in 2006 and reported that $55 \%$ of women in Rasht city and $46 \%$ of women in Qazvin city added salt to their meal (30). However, the second study conducted in 2011 and showed that 13.5\% of women referring to the healthcare centers in Yazd city used a saltshaker during their meal (31). These findings show that the percentage of Iranian women who add table salt to their foods has a decreasing trend.

The results of this study indicated that from 2001 to 2016, the prevalence of hypertension increased with age, and the highest prevalence was observed in those over 70 years of age. Moreover, the risk of getting HTN increased for every year of increase in age between $7 \%-12 \%$. A recent study also found that every one year increase in age of postmenopausal women was associated with a $7 \%$ increased risk of CVDs (26).

The present study showed that the prevalence of hypertension did not change significantly from 2001 to 2016 , but the prevalence of prehypertension in postmenopausal women has been decreased, especially in the age group of 40 to 60 years. Contrary to expectations and despite the unchanged prevalence of hypertension in postmenopausal women during the 15 
study years, over $50 \%$ of postmenopausal women in this study were hypertensive in all three surveys. Also, despite the decreased prevalence of prehypertension, still more than one-third of postmenopausal women were prehypertensive. In a study in China in 2014 , the prevalence of hypertension was $43.6 \%, 62.3 \%$, and $75.5 \%$ among postmenopausal women in the age groups of 45-54, 55-64, and over 65 years old (32). A recent study also showed that the prevalence of hypertension among postmenopausal women was $47.1 \%$ in Argentina (33). Also a study showed that $55.84 \%$ of Japanese women over 50 had prehypertension (35). Studies in Iran also reported that $65.5 \%$ and $33.9 \%$ of Iranian postmenopausal women were hypertensive in 2008 and 2013, respectively $(14,15)$.

According to the results of this study, the prevalence of hypertension awareness, regular use of medications, and wellcontrolled hypertension were constantly significantly increasing from 2001 to 2016. In another study on people with hypertension in Isfahan, Iran, the prevalence of hypertension of awareness, regular use of medications, and well-controlled hypertension were $69.2 \%, 92.4 \%$ and $59.9 \%$ respectively (35). Our findings are also consistent with a study on the American adult population in which the prevalence of hypertension awareness and well-controlled hypertension has been significantly increased between the years 1999 and 2010 (28). Surprisingly, a study in Canada has reported that the prevalence of hypertension did not significantly change in the last two decades. Although , in 1992, the rates of hypertension awareness, and good treatment and control were $56.9 \%, 34.6 \%$ and $13.2 \%$, and then in 2009 increased to $82.5 \%, 79.8 \%$ and $64.6 \%$, respectively (36). In a cross-sectional study on the data of cohort studies published from 2004 to 2008, the prevalence of awareness and risk factors of high blood pressure in 50045 Iranian people aged 40-75 years living in Golestan province in northeastern Iran (20\% of those living in urban areas and $80 \%$ living in rural areas), after adjusting for age, the overall prevalence of hypertension was $41.8 \%$. The prevalence of hypertension was significantly higher in women than in men (44.1\% vs. $33.1 \%$ ). Of those with hypertension, $46.2 \%$ were aware of their illness and $17.6 \%$ had received antihypertensive drugs. Among those who were under medical treatment, $32.1 \%$ could control their disease. The rate of hypertension awareness was higher in women, older adults, those who were overweight and obese, and those with higher levels of wealth. High blood pressure was directly associated with female gender, increased body mass index, Turkmen ethnicity and physical inactivity, but it was inversely correlated with black tea drinking and wealth (37).

The present study showed that the rate of regular medication intake was $73.7 \%$ in 2001 and increased to $86.6 \%$ in 2016 . Moreover, the rates of well controlled hypertension and hypertension awareness in postmenopausal women have respectively increased from $28 \%$ to $62 \%$ and $75 \%$ to $87 \%$ from the first to the third survey. These significant increasing trends might be attributed a number of factors such as improvements in women's education and employment status, improved attitudes toward health maintenance, and increased accessibility to healthcare and medical facilities in the country. Moreover, as Sabouhi et al., (2011) reported, an increase in multimodal and communitywide health promotion and health education programs, free screening projects, community-based health interventions, and increase in the number of healthcare centers might have contributed in this regard(38).

Besides, as the present study showed, during the last two decades Iranian women (including postmenopausal women) became more educated, gained higher levels of financial independence and increased their community participation which may consequently affect their awareness, treatment and control of their blood pressure. A study in the United States examined 10-year trends in the prevalence, treatment, and control of hypertension showed that the rate of hypertension awareness and hypertension control in men and women were $69.7 \%$ and $80.7 \%$ and $43 \%$ and $56 \%$, respectively. These trends have also been increased from 1999 to 2010 (28).

\section{Limitations and strengths}

The limitations of this study are fully described in another article (35). In addition to these, other limitations of this study are: age at menopause was self-reported and may be subject to recall bias. And finally, women with a history of hysterectomy were not excluded.The strengths of the study include observing the standard conditions for measuring blood pressure.

\section{Conclusions}


This study showed that about half of postmenopausal women in the rural areas of Iran had hypertension and more than $42 \%$ of them were prehypertensive in 2001-2016. These findings signify the need for effective preventive, educational and screening interventions in this group. Given the fact that women make up half of the population and the age of the population is rising, and as the number of postmenopausal women is constantly rising, and due to the relatively high prevalence of hypertension and cardiovascular risk factors in these women, it is crucial to implement prevention, treatment, screening, and follow up programs in postmenopausal women. Moreover, as the study revealed, postmenopausal women in our community are obese are more confronted with diabetes mellitus, hyperlipidemia, prehypertension and hypertension. Then, policymakers should implement some strategies in order to improve the women's lifestyle.

\section{Abbreviations}

WHO: world health organization

JNC-7: The Seventh Report of the Joint National Committee on Prevention, Detection, Evaluation, and Treatment of High Blood Pressure

SBP: Systolic Blood Pressure

DBP: Diastolic Blood Pressure

BMI: Body mass index

HTN: Hypertension

\section{Declarations}

\section{- Ethics approval and consent to participate}

The ethical code of this research project is IR.MUI.REC.2016.3.790 approved by Isfahan University of Medical Sciences. Presence in research environments was done by obtaining and presenting an introduction letter from the cardiovascular research institute of Isfahan, Iran and HTN Research Centre. Written informed consent was obtained from each participant. All ethical standards were performed.

\section{- Consent for publication}

Written informed consent for publication of their clinical details was obtained from the clients. A copy of the Consent form is available for review by the review of BMC Public Health journal.

\section{- Availability of data and material}

The data that support the findings of this study are available from Isfahan Cardiovascular Research Center, Isfahan University of Medical Sciences but restrictions apply to the availability of these data, which were used under license for the current study, and so are not publicly available. Data are however available from the authors upon reasonable request and with permission of Isfahan Cardiovascular Research Center, Isfahan University of Medical Sciences.

\section{- Competing interests}

Authors have no compete of interests.

\section{- Funding}


This study has been funded by the Iranian National Science Foundation and registered under number 91004751 . The National Network of Cardiovascular Research and the Isfahan University of Medical Sciences as well as Isfahan Cardiovascular Research Institute have funded the study too. This article has been extracted from PhD thesis, No. 394,790 approved at Isfahan University of Medical Sciences. The mentioned centers have only provided a financial support in this study.

\section{- Authors' contributions}

M.E, A.K, N.S, H. A: Designed and directed the project and developed the theoretical framework.

1. E, A. K, N. S, H. A: Implemented, data collected and performed the measurements,

M.E, A.K, N.S: Were involved in planning and supervised the work.

1. E, N.K, A. F: Analyzed the data.

2. E, A. K, N.K and A. F: Wrote the article.

3. E, A. K, N. S, N.K, A. F and H. A: Aided in interpreting the results and worked on the manuscript. All the authors approved the final version of the manuscript.

\section{- Acknowledgements}

The authors would like to thank and acknowledge Isfahan Hypertension Research Centre and people who assisted in this study.

\section{References}

1. Li H, Yan X, Deng X, Yang L, Zhao S, Zou J, Luo Y, Cao S. A cross-sectional study of the prevalence, awareness, treatment and control of hypertension in Shenzhen, China. BMJ open. 2017 Jun 1;7(6):e015206.

2. Kim SJ, Lee J, Nam CM, Jee SH, Park IS, Lee KJ, Lee SY. Progression rate from new-onset pre-hypertension to hypertension in Korean adults. Circulation Journal. 2011;75(1):135-40.

3. Ferguson TS, Younger NO, Tulloch-Reid MK, Wright MB, Ward EM, Ashley DE, et al. Prevalence of prehypertension and its relationship to risk factors for cardiovascular disease in Jamaica: Analysis from a cross-sectional survey. BMC Cardiovasc Disord (2008); 8: 20.

4.Engberding N, Wenger NK. Management of hypertension in women. Hypertension Research (2012) 35, 251-260; doi:10.1038/hr.2011.210

5. Mozaffarian D, Benjamin EJ, Go AS, Arnett DK, Blaha MJ, Cushman M, Das SR, de Ferranti S, Després JP, Fullerton HJ, Howard VJ. Heart disease and stroke statistics-2016 update: a report from the American Heart Association. Circulation. 2015 Jan 1:CIR-0000000000000350.

6. Rubinstein, $H$. The meanings of menopause: identifying the bio-psycho-social predictors of the propensity for treatment at menopause (Doctoral thesis) (2013) https://doi.org/10.17863/CAM.16470

7. Nuzzo, A., Rossi, R. \& Modena, M. G .Hypertension alone or related to the metabolic syndrome in postmenopausal women, Expert Review of Cardiovascular Therapy (2010) 8:11, 1541-1548, DOI: 10.1586/erc.10.147

8. Ferguson TS, Younger NO, Tulloch-Reid MK, Wright MB, Ward EM, Ashley DE, et al. Prevalence of prehypertension and its relationship to risk factors for cardiovascular disease in Jamaica: Analysis from a cross-sectional survey. BMC 
Cardiovascular Disorder (2008) 8: 20.

9. Zambrana R E, Lopez L, Dinwiddie G Y, Ray R M, PhillipsL S, Trevisan M, Wassertheil-Smoller S. Prevalence and Incident Prehypertension and Hypertension in Postmenopausal Hispanic Women: Results from the Women's Health Initiative. American Journal of Hypertension 27(3) (2014)372-7-81

10. Speroff L, Glass RH, Kase NG, eds. Clinical gynecologic endocrinology and infertility. Sixth Edition. Philadelphia: Lippincott Williams \& wilkson Company; (2005) chapter 17, p623.

11.Barbara L. Hoffman M D. Williams Gynecology. th ed (2016) chapter 21, p471.

12. Amier Ahmad, Suzanne Oparil. Hypertension in Women; Recent Advances and Lingering Questions. Hypertension. (2017)70:19-26. DOI: 10.1161/HYPERTENSIONAHA.117.08317

13. Mojahedi, M., Hami, M., Shakeri, M., Hasani, M., Ahadi, M. The Prevalence and related risk factors of hypertension in young adults in Mashhad Hypertension in young adults. medical journal of mashhad university of medical sciences (2015) 58(5): 252-257. doi: 10.22038/mjms.2015.4742

14.Pourmoghaddas M,khosravi A,Kelishadi R,SarrafzadeganN,Shirani Sh,Ansari R,Sabet B. Trends in blood pressure level,prevalence and control of hypertension in Isfahan,Iran.Iranian heart Journal 2004;5(1,2):33-38

15. Eghbali-Babadi M, Khosravi A, Feizi A, Sarrafzadegan N. Design and implementation of a combined observational and interventional study: Trends of prevalence, awareness, treatment and control hypertension and the effect of expanded chronic care model on control, treatment and self-care. ARYA Atheroscler 2017; 13) 5(:PP 211-220

16. Sarrafzadegan N, Baghaei A, Sadri G, Kelishadi R, Malekafzali H, Boshtam M, et al. Isfahan healthy heart program: Evaluation of comprehensive, community-based interventions for non-communicable disease prevention. Prevention and Control 2006; 2(2): 73-84.

17. Khosravi A, Mehr GK, Kelishadi R, Shirani S, Gharipour M, Tavassoli A, Noori F, Sarrafzadegan N. The impact of a 6-year comprehensive community trial on the awareness, treatment and control rates of hypertension in Iran: experiences from the Isfahan healthy heart program. BMC cardiovascular disorders. 2010 Dec;10(1):61.

18. Eghbali M, Khosravi A, Feizi A, Mansouri A, Mahaki B, Sarrafzadegan N. Prevalence, awareness, treatment, control, and risk factors of hypertension among adults: a cross-sectional study in Iran. Epidemiology and health. 2018;40.

19. Neuhauser, H.; Adler, C.; Rosario, A.; Diederichs, C.; Ellert, U., Hypertension prevalence, awareness, treatment and control in Germany 1998 and 2008-11. Journal of human hypertension 2015, 29 (4), 247.

20. Gee ME, Campbell N, Sarrafzadegan N, Jafar T, Khalsa TK, Mangat B, Poulter N, Prabhakaran D, Sonkodi S, Whelton PK, Woodward M. Standards for the uniform reporting of hypertension in adults using population survey data: recommendations from the World Hypertension League Expert Committee. The Journal of Clinical Hypertension. 2014 Nov;16(11):773-81.

21. Hackam DG, Quinn RR, Ravani P, Rabi DM, Dasgupta K, Daskalopoulou SS, et al. The 2013 Canadian Hypertension Education Program recommendations for blood pressure measurement, diagnosis, assessment of risk, prevention, and treatment of hypertension. Can J Cardiol 2013,29:528-542.

22.Golshiri P, Akbari M, Abdollahzadeh MR. Age at natural menopause and related factors in Isfahan, Iran. Journal of menopausal medicine. 2016 Aug 1;22(2):87-93

23.Rajaeefard A, Mohammad-Beigi A, Mohammad-Salehi N. Estimation of natural age of menopause in Iranian women: $A$ meta-analysis study . koomesh. 2011; 13 (1):1-7 
24. NCD Risk Factor Collaboration. (2016). "Worldwide trends in diabetes since 1980: a pooled analysis of 751 populationbased studies with 4. 4 million participants." The Lancet 387(10027): 1513-1530.

25. Xiu-Jun Meng; Guang-Hui Dong,; Da Wang,; Miao-Miao Liu,; Yu-Qin Liu,;Yang Zhao,; Wei-Wei Deng,; Shen Tian,; Xin Meng,; Hai-Yan Zhang,. Epidemiology of Prehypertension and Associated Risk Factors in Urban Adults From 33 Communities in China. Circulation Journal Vol.76, April 2012:901-6.

26. Zhou Y, Zhou X, Guo X, Sun G, Li Z, Zheng L, Yang H, Yu SH, Li W, Zou L, Sun Y. Prevalence and risk factors of hypertension among pre- andpost-menopausal women: A cross-sectional study in a rural areaof northeast Chin. Maturitas 80 (2015) 282-287.

27. Chazova IE, Zhernakova I, Oshchepkova EV, Shal'nova SA, larovaia EB, Konradi AO, Boĭtsov SA. Prevalence of cardiiovascular risk factors in Russian population of patients with arterial hypertension. Kardiologiia. 2014;54(10):4-12.

28. Fangjian Guo, Di He, Wei Zhang, R. Grace Walton. Trends in Prevalence, Awareness, Management, and Control of Hypertension among United States Adults, 1999 to 2010. JACC Vol. 60, No. 7, 2012: 599-606.

29. Zhou B, Bentham J, Di Cesare M, Bixby H, Danaei G, Cowan MJ, Paciorek CJ, Singh G, Hajifathalian K, Bennett JE, Taddei C. Worldwide trends in blood pressure from 1975 to 2015: a pooled analysis of 1479 population-based measurement studies with 19. 1 million participants. The Lancet. 2017 Jan 7,389(10064):37-55.

30. Agheli N, Asef Zade S, Rajabi M, Ghodous A. Study of calories and macronutrients intake in people of Rasht and Qazvin. J Qazvin Univ Med Sci 2006; 10(1): 25-30.[Persian]

31. Motlagh Z, Mazloomy S, Mozaffari Khosravi M, Morowatisharifabad M, Askarshahi H. Salt Intake among Women Refer to Medical Health Centers, Yazd Iran, 2011. J Shahid Sadoughi Univ Med Sci; 19(4): 550-60

32. Zhou Y, Zhou X, Guo X, Sun G, Li Z, Zheng L, Yang H, Yu SH, Li W, Zou L, Sun Y. Prevalence and risk factors of hypertension among pre- andpost-menopausal women: A cross-sectional study in a rural areaof northeast Chin. Maturitas 80 (2015) 282-287.

33. Zilberman J M, Cerezo G H, Sueldo M D, Fernandez-Perez C, Martell-Claros N, Vicario A. Association Between Hypertension, Menopause, and Cognition in Women. The Journal of Clinical Hypertension.2015; 17 (12 ):PP 970-976

34. Muchanga MJ, Lepira FB, Tozin R, Mbelambela EP, Ngatu NR, Sumaili EK, Makulo JR, Suganuma N. Prevalence and risk factors of pre-hypertension in Congolese pre and postmenopausal women. African health sciences. 2016;16(4):979-85.

35.Babadi, M. E., A. Khosravi, A. Feizi, A. Mansouri, B. Mahaki and N. Sarrafzadegan (2018). "Prevalence, awareness, treatment, control, and risk factors of hypertension among adults: a cross-sectional study in Iran."

36. McAlister FA, Wilkins K, Joffres M, Leenen FH, Fodor G, Gee M, Tremblay MS, Walker R, Johansen H, Campbell N. Changes in the rates of awareness, treatment and control of hypertension in Canada over the past two decades. Canadian Medical Association Journal. 2011 Jun 14;183(9):1007-13.

37. Malekzadeh, M. M., A. Etemadi, F. Kamangar, H. Khademi, A. Golozar, F. Islami, A. Pourshams, H. Poustchi, B. Navabakhsh and M. Naemi (2013). "Prevalence, awareness and risk factors of hypertension in a large cohort of Iranian adult population." Journal of hypertension 31(7): 1364.

38. Sabouhi F, Babaee S, Naji H, Zadeh AH. Knowledge, awareness, attitudes and practice about hypertension in hypertensive patients referring to public health care centers in Khoor \& Biabanak. Iranian journal of nursing and midwifery research. 2011;16(1):34. 
Tables

Table 1: Demographic characteristics, Clinical Basis Information and Cardiovascular risk factors in postmenopausal women between 2000 and 2001, 2006 to 2007, 2015 to 2016

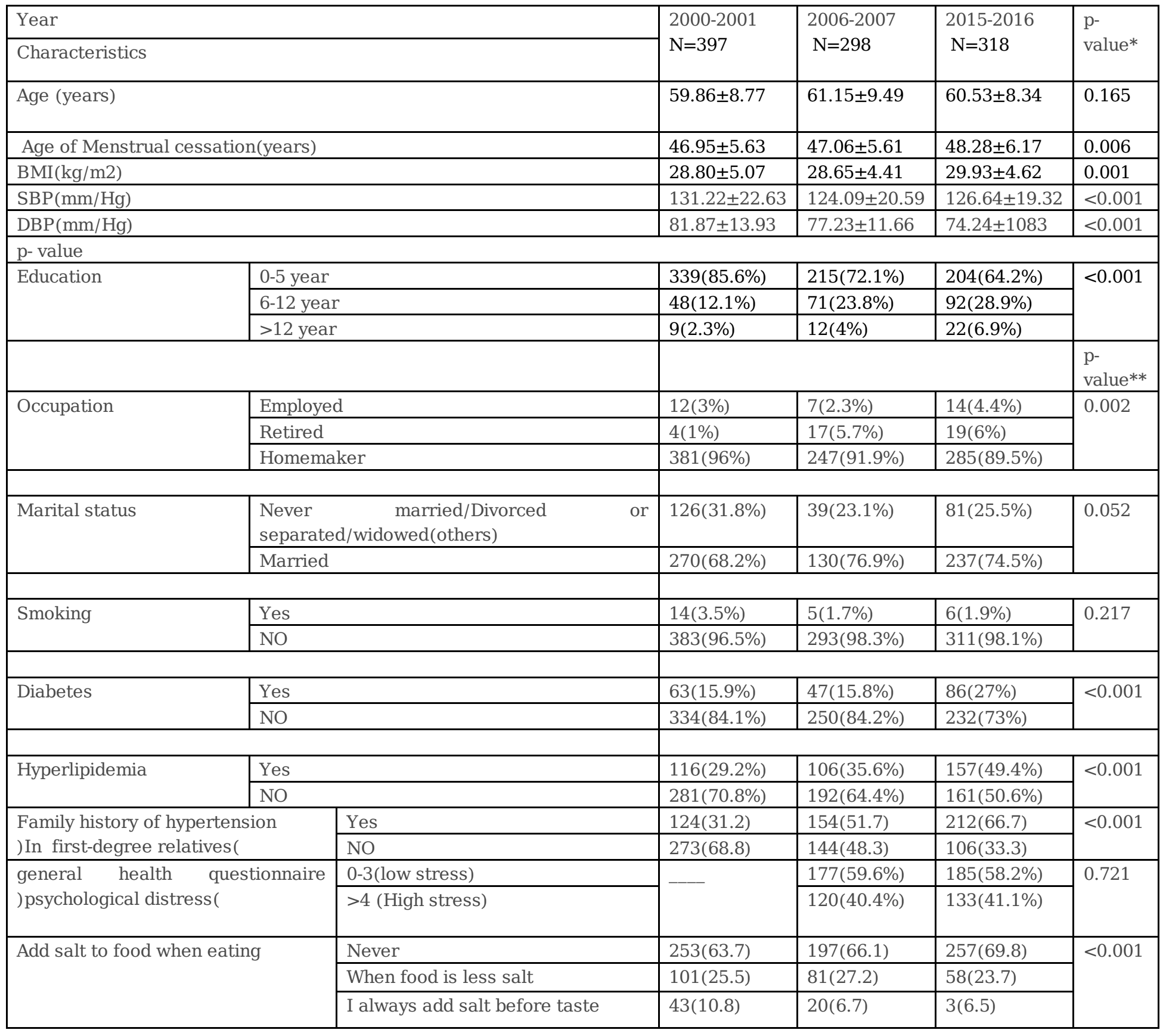

Data was presented as mean \pm standard deviation for continuous variables and frequency (percentage) for categorical variables. Pvalues were derived from one way ANOVA for continuous variables and chi-square test for categorical variables as appropriate

Table 2: Trend of hypertension and prehypertension in age category menopausal women between 2000 and 2001,2006 to 2007,2015 to 2016 


\begin{tabular}{|l|l|l|l|l|l|l|l|l|}
\hline Year & \multicolumn{2}{|l|}{$\begin{array}{l}\text { 2000-2001 } \\
\text { N (\%) }\end{array}$} & \multicolumn{2}{l|}{$\begin{array}{l}\text { 2006-2007 } \\
\text { N }\end{array}$} & & \multicolumn{2}{l|}{$\begin{array}{l}\text { N (\%) } \\
\text { 2000-2016 }\end{array}$} \\
\hline $\begin{array}{l}\text { Age group } \\
\text { (years) }\end{array}$ & Pre.HTN & HTN & Pre.HTN & HTN & Pre.HTN & HTN & Pre.HTN & HTN \\
\hline Total & $112(59.6)$ & $209(52.6)$ & $81(53.3)$ & $146(49.0)$ & $65(42.2)$ & $164(51.6)$ & 0.006 & 0.628 \\
\hline$<60$ & $66(55.9)$ & $80(40.4)$ & $44(47.3)$ & $46(33.1)$ & $33(31.4)$ & $59(36.0)$ & 0.001 & 0.374 \\
\hline $\mathbf{6 0 - 7 0}$ & $31(62.0)$ & $88(63.8)$ & $22(57.9)$ & $56(59.6)$ & $25(67.9)$ & $60(61.9)$ & 0.686 & 0.811 \\
\hline$>70$ & $15(75.0)$ & $41(67.2)$ & $15(71.4)$ & $44(67.7)$ & $7(58.3)$ & $45(78.9)$ & 0.597 & $0 / 284$ \\
\hline p-value & 0.253 & $<0.001$ & 0.109 & $<0.001$ & $<0.001$ & $<0.001$ & & \\
\hline
\end{tabular}

Data was presented as frequency (percentage). P-values were derived from chi-square test

Table 3: The process of awareness, treatment and control of hypertension in menopausal women with hypertension

\begin{tabular}{|c|c|c|c|c|c|c|}
\hline \multicolumn{2}{|l|}{ Year } & $2000-2001$ & $2006-2007$ & 2015-2016 & P VALUE & $\begin{array}{l}\text { POST HOC } \\
\text { BON... }\end{array}$ \\
\hline \multirow[t]{2}{*}{ Awareness } & YES & $156(74.6 \%)$ & $113(77.4 \%)$ & $142(86.6 \%)$ & \multirow[t]{2}{*}{0.015} & - \\
\hline & NO & $53(25.4 \%)$ & $33(22.6 \%)$ & $22(13.4 \%)$ & & $\begin{array}{l}2001-2007 \\
2007-2016\end{array}$ \\
\hline \multirow[t]{3}{*}{ Pharmacological treatment } & Regular use & $154(73.7 \%)$ & $105(71.9)$ & $142(86.6)$ & \multirow[t]{3}{*}{0.009} & - \\
\hline & Irregular use & $42(20.1 \%)$ & $33(22.6)$ & $20(12.2)$ & & $\begin{array}{l}2001-2016 \\
2007-2016\end{array}$ \\
\hline & NO & $13(6.2 \%)$ & $8(5.5)$ & $2(1.2)$ & & $\begin{array}{l}2001-2016 \\
2007-2016\end{array}$ \\
\hline \multirow[t]{2}{*}{ HTN control } & YES & $45(28.8 \%)$ & $57(50.4 \%)$ & $88(62.0 \%)$ & \multirow[t]{2}{*}{$<0.001$} & $\begin{array}{l}2001-2007 \\
2007-2016\end{array}$ \\
\hline & NO & 111(71.2\%) & $56(49.6 \%)$ & $54(38.0 \%)$ & & - \\
\hline
\end{tabular}

Data was presented as frequency (percentage) for categorical variables. P-values were derived from chi-square test and post hoc, bonferroni for categorical variables as appropriate

Table 4: Cardiovascular risk factors in postmenopausal women with hypertension 


\begin{tabular}{|c|c|c|c|c|c|c|}
\hline \multicolumn{2}{|l|}{ Year } & $2000-2001$ & 2006-2007 & $2015-2016$ & P VALUE & $\begin{array}{l}\text { POST HOC } \\
\text { BONFERONI }\end{array}$ \\
\hline \multicolumn{2}{|l|}{ Age (years) } & $61.97(8.55)$ & 63.99(8.74) & $63.53(8.15)$ & 0.058 & --- \\
\hline BMI (kg/m2) & & $29.45(5.12)$ & $29.09(4.43)$ & $30.38(4.79)$ & 0.051 & ---- \\
\hline \multirow[t]{2}{*}{ Diabetes } & Yes & $41(19.6 \%)$ & $32(21.9 \%)$ & $57(34.8 \%)$ & \multirow[t]{2}{*}{0.002} & $\begin{array}{l}2001-2016 \\
2007-2016\end{array}$ \\
\hline & No & $168(80.4 \%)$ & 114(78.1\%) & $107(65.2 \%)$ & & $\begin{array}{l}2001-2016 \\
2007-2016\end{array}$ \\
\hline \multirow[t]{2}{*}{ Hyperlipidemia } & Yes & $72(34.4 \%)$ & $64(43.8 \%)$ & $95(57.9 \%)$ & \multirow[t]{2}{*}{$<0.001$} & $\begin{array}{l}2001-2016 \\
2007-2016\end{array}$ \\
\hline & No & $137(65.6 \%)$ & $82(56.2 \%)$ & $69(42.1 \%)$ & & $\begin{array}{l}2001-2016 \\
2007-2016\end{array}$ \\
\hline \multirow[t]{2}{*}{$\begin{array}{l}\text { Family history of hypertension } \\
\text { ) In first-degree relatives( }\end{array}$} & Yes & $81(38.8)$ & $79(54.1)$ & 116(70.7) & \multirow[t]{2}{*}{$<0.001$} & $\begin{array}{l}2001-2007 \\
2007-2016 \\
\end{array}$ \\
\hline & No & $128(61.2)$ & $67(45.9)$ & 48(29.3) & & - \\
\hline \multirow[t]{2}{*}{ Smoking } & Yes & $8(3.8 \%)$ & $2(1.4 \%)$ & $2(1.2 \%)$ & \multirow[t]{2}{*}{0.176} & \multirow[t]{2}{*}{---- } \\
\hline & No & $201(96.2 \%)$ & 144(98.6\%) & $161(98.8 \%)$ & & \\
\hline
\end{tabular}

P-values were derived from One way ANOVA for continuous variables and chi-square test and post hoc, bonferroni test for categorical variables as appropriate

Table 5: Association between hypertension and related risk factors in menopausal women hypertension

\begin{tabular}{|c|c|c|c|c|c|c|c|c|c|c|c|c|c|}
\hline \multicolumn{2}{|l|}{ Year } & \multicolumn{4}{|c|}{$2000-2001$} & \multicolumn{4}{|c|}{ 2006-2007 } & \multicolumn{4}{|c|}{ 2015-2016 } \\
\hline & & \multirow{2}{*}{$\begin{array}{l}P \\
\text { value } \\
\end{array}$} & \multirow[t]{2}{*}{ OR } & \multicolumn{2}{|c|}{ 95\% C.I.for OR } & \multirow{2}{*}{$\begin{array}{l}P \\
\text { value }\end{array}$} & \multirow[t]{2}{*}{ OR } & \multicolumn{2}{|c|}{ 95\% C.I.for OR } & \multirow{2}{*}{$\begin{array}{l}P \\
\text { value }\end{array}$} & \multirow[t]{2}{*}{ OR } & \multicolumn{2}{|c|}{ 95\% C.I.for OR } \\
\hline & & & & Lower & Upper & & & Lower & Upper & & & Lower & Upper \\
\hline \multicolumn{2}{|l|}{ Age (years) } & $<0.001$ & 1.077 & 1.049 & 1.106 & $<0.001$ & 1.070 & 1.040 & 1.101 & $<0.001$ & 1.125 & 1.086 & 1.167 \\
\hline \multicolumn{2}{|l|}{ BMI (kg/m2) } & .005 & 1.067 & 1.020 & 1.117 & .048 & 1.060 & 1.001 & 1.122 & .044 & 1.059 & 1.002 & 1.119 \\
\hline \multirow[t]{2}{*}{ Diabetes } & Yes & \multirow[t]{2}{*}{.188} & \multirow[t]{2}{*}{1.518} & \multirow[t]{2}{*}{.815} & \multirow[t]{2}{*}{2.829} & \multirow[t]{2}{*}{.069} & \multirow[t]{2}{*}{1.938} & \multirow[t]{2}{*}{.950} & \multirow[t]{2}{*}{3.956} & \multirow[t]{2}{*}{.045 } & \multirow[t]{2}{*}{1.848} & \multirow[t]{2}{*}{1.014} & \multirow[t]{2}{*}{3.367} \\
\hline & $\begin{array}{l}\text { No } \\
\text { (Ref) }\end{array}$ & & & & & & & & & & & & \\
\hline \multirow[t]{2}{*}{ Hyperlipidemia } & Yes & \multirow[t]{2}{*}{.250} & \multirow[t]{2}{*}{1.337} & \multirow[t]{2}{*}{.815} & \multirow[t]{2}{*}{2.191} & \multirow[t]{2}{*}{.175} & \multirow[t]{2}{*}{1.453} & \multirow[t]{2}{*}{.847} & \multirow[t]{2}{*}{2.493} & 163 & 1.450 & .860 & 2.444 \\
\hline & $\begin{array}{l}\text { No } \\
\text { (Ref) }\end{array}$ & & & & & & & & & & & & \\
\hline $\begin{array}{l}\text { Family history } \\
\text { of } \\
\text { hypertension }\end{array}$ & Yes & $<0.001$ & 2.433 & 1.501 & 3.943 & .110 & 1.520 & 909 & 2.541 & .001 & 2.534 & 1.434 & 4.476 \\
\hline $\begin{array}{l}\text { ) In first- } \\
\text { degree } \\
\text { relatives( }\end{array}$ & $\begin{array}{l}\text { No } \\
\text { (Ref) }\end{array}$ & & & & & & & & & & & & \\
\hline
\end{tabular}

P-values were derived from Logistic regression

\section{Figures}



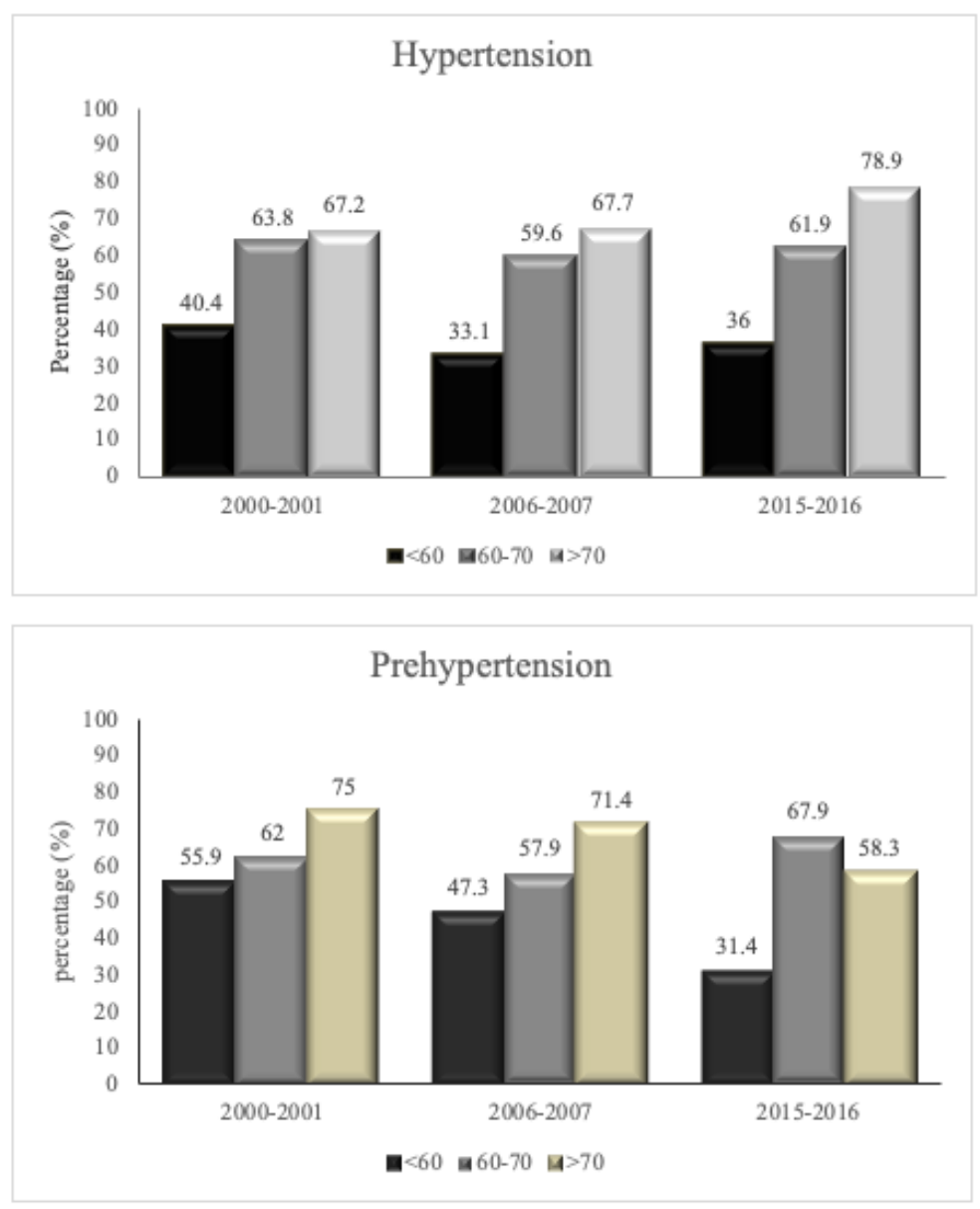

\section{Figure 1}

The prevalence of hypertension \& prehypertension, among the menopausal women, Isfahan, Iran, 2016. Note: The error bars indicate $95 \% \mathrm{Cls}$ for the prevalence. 